\title{
VERIFICATION OF THE CALENDAR DAYS OF THE JOSEON DYNASTY
}

\author{
Ki-Won Lee ${ }^{1}$, Young Sook Ahn ${ }^{2}$, And Byeong-Hee Minn ${ }^{2,3}$ \\ ${ }^{1}$ Catholic University of Daegu, 13-13 Hayang-ro, Hayang-eup, Gyeongsan 712-702, Korea \\ E-mail : leekw@cu.ac.kr \\ ${ }^{2}$ Korea Astronomy and Space Science Institute, 776 Daedeokdae-ro, Yuseong-gu, Daejeon 305-348, Korea \\ E-mail : ysahnn@kasi.re.kr,bhmin@kasi.re.kr \\ 3 Department of Astronomy and Space Science, Chungbuk National University, Cheongju 361-763, Korea \\ (Received January 17, 2012; Revised June 25, 2012; Accepted July 31, 2012)
}

\begin{abstract}
Astronomical data making such as forming a calendar, period of day, determining the time of rising/setting of the sun and the onset of twilight are essential in our daily lives. Knowing the calendar day of the past is particularly crucial for studying the history of a clan or a nation. To verify previous studies in the calendar day of the Joseon dynasty $(1392-1910)$, we investigate the sexagenary cycle of the new moon day (i.e., the first day in a lunar month) by using sources such as results of the calculations using the Datong calendar (a Chinese Calendar of the Ming Dynasty) and the data of Baekjungryeok (a Perpetual Calendar; literally, a one hundred-year almanac). Compared with the study of Ahn et al., we find that as many as 17 sexagenary cycles show discrepancies. In the cases of nine discrepancies, we find that the sexagenary cycles of this study are identical to those of the almanacs at that time. In addition, we study five sexagenary cycles by using the historical accounts of Joseon Wangjo Sillok (Annals of the Joseon Dynasty), Seungjeongwon Ilgi (Daily Reports of Royal Secretariat), Chungung Ilgi (Logs of Crown Prince), and so forth. For the remaining discrepancies, we present historical literature supporting the results of this study. This study will greatly contribute to the identification of the lunisolar calendar days during the Joseon dynasty as the dates of the modern (i.e., Gregorian) calendar.
\end{abstract}

Key words : historical astronomy — calendar day — calendar: lunisolar; Julian; Gregorian — period: Joseon dynasty

\section{INTRODUCTION}

The astronomical calendar has been improved in order to accurately calculate calendar data (e.g., calendar day, sunrise and sunset times, and moonrise and moonset times), which is essential to our daily lives. Although most countries, including Korea, currently adopt the Gregorian calendar, East Asian countries traditionally used the lunisolar calendar, which reflects the solar motion within a lunar calendar (Lee 1985). The length of a month or a year is defined differently depending on the calendar system that is implemented. Hence, in order to understand the history of a clan or a nation, it is important to accurately identify past calendar days as the dates of the modern calendar.

There have been many studies on the calendar days of Korea, ranging from the Three Kingdoms to the Joseon dynasty (Han 1987, 2001; Yang et al. 1999; Ahn et al. 2000, 2009a,b,c) Owing to the lack of literature that corresponds to earlier periods, the calendar days of the early periods are more ambiguous than those of the later periods. Even historical documents of the Joseon dynasty are not sufficient for a complete study on the calendar days of the dynasty, although works such as Joseon Wangjo Sillok ${ }^{1 *}$ (Annals of the Joseon Dynasty; hereafter Sillok), Seungjeongwon Ilgi² (Daily Records of the Royal Secretariat; hereafter Ilgi), Jeungbo Munheon Bigo ${ }^{3}$ (Explanatory Notes of Literary Document; hereafter Bigo), etc., remain.

The aim of our study is to verify previous studies of the calendar days of Korea. Initially, we re-examine the calendar days of the Joseon dynasty, compare them with the results of a recent study, and subsequently debate the days that reveal a discrepancy. In Section 2, we describe the method that was used for re-examining the calendar days of the Joseon dynasty, and list the days that reflect discrepancies within the study. In Section 3, we provide an argument for each discrepancy using various sources. Finally, in Section 4, we summarize the results of this study.

\footnotetext{
* For the terms marked with superscript Arabic numbers, we present its Chinese character and meaning in Appendix A to-
} gether with the abbreviation used in this study. 


\section{METHODOLOGY}

A calendar day varies depending on the astronomical calendar used. Thus, the best way to study calendar days is to use the astronomical calendar of the corresponding period. In this case, however, we have to know the detailed contents of the calendar, and the exact period during which it was used.

On the other hand, an astronomical almanac contains astronomical data that include the calendar days calculated by an astronomical calendar. This means that, we do not need to know the detailed contents and the exact usage period of the calendar. Hence, using an astronomical almanac with reference to any given time period is practically the best way to study calendar days of the past.

However, previous studies have mainly drawn from the sexagenary cycle of the new moon day (i.e., the first day of a lunar month) from Sillok because the databases for other historical documents, such as astronomical almanacs, were not available then. In addition, some studies used the results of modern astronomical methods in order to estimate the new moon day.

Recently, Korea Astronomy and Space Science Institute (hereafter, KASI) has constructed an online database for the Korean astronomical almanac ${ }^{\dagger}$ (see Lee et al. 2011). In the database, the annual astronomical almanacs cover approximately 140 years for around 500 years of the Joseon dynasty, and the oldest one is the almanac for the year 1607. The oldest astronomical almanac in Korea is the Datong almanac for the year 1580, which is preserved in the National Folk Museum (Kim 2002). Perpetual almanacs, such as Baekjungryeok ${ }^{4}$, Cheonseryeok ${ }^{5}$, and Manseryeok ${ }^{6}$ (literally, One Hundred-Year, One Thousand-Year, and Ten Thousand-Year Almanacs, respectively) are also included in the database and cover approximately 370 years. The oldest perpetual almanac is Baekjungryeok ${ }^{4}$, which contains one hundredyears of calendar data ranging from 1542 to 1641 (Lee 1997).

During the period of the Joseon dynasty, two primary Chinese lunisolar calendars were used until 1896: The Datong calendar ${ }^{7}$ of the Ming dynasty, and the Shixian calendar ${ }^{8}$ of the Ching dynasty. According to the work of Lee et al. (2010, hereafter LEE10), the Datong calendar ${ }^{7}$ was enforced during the periods from 1392 to 1653 , and from 1667 to 1669 in the Joseon dynasty.

In this paper, we divided the Joseon dynasty into two periods according to the calendars of Datong ${ }^{7}$ and Shixian ${ }^{8}$. Subsequently, we investigated the new moon day by using the results of the Datong calendar ${ }^{7}$ study (i.e., LEE10) for the former period, and the data of Baekjungryeok ${ }^{4}$ for the latter one. Following this, we compared these results with the conclusions

${ }^{\dagger}$ http://astro.kasi.re.kr of Ahn et al. 2009a (hereafter AHN09). We chose Baekjungryeok $^{4}$ because it contains the past calendar days on the basis of the compilation time, whereas Chenseryeok $^{5}$ or Manseryeok ${ }^{6}$ include the future calendar days (Kim 2010).

In the lunisolar calendar, the new moon day was used as the first day in each month. Hence, one month was 29 or 30 days because the synodic month comprises about 29.53 days, whereas a lunar year was twelve months, which is same as a solar year. Thus, approximately one intercalary month per three years was inserted in order to compensate for the difference of the solar year. In addition, one of sixty permutations, often ten 'Heavenly Stems' and the twelve 'Earthly Branches' (sexagenary cycle, hereafter), were assigned to each year, month (except intercalary month), and day, and the sexagenary cycles were repeatedly used (for more details, refer to KASI 2010). In appendix B, we present the sexagenary cycles, which are expressed in Chinese characters and indicated by Arabic numbers. In this paper, we will express the sexagenary cycle (shortly SC) using the corresponding Arabic number.

As mentioned above, since one lunar month has 29 or 30 days, we can verify the calendar day by investigating the SC of the new moon day in each month. In Table 1, we summarize SCs by showing the disagreements within the AHN09 study. In the table, the columns 1, 2 , and 3 are the calendar dates in the lunisolar calendar. Unless otherwise mentioned, all dates are given as the lunisolar calendar. Columns 4 and 5 are SCs of the day in AHN09 and in this study, respectively. The last column represents the sources used for verifying the SC of the day, which is discussed in the next section.

\section{ARGUMENT}

\subsection{March 1397, May 1399, and December 1440}

As seen in Table 1, AHN09 identified the SC of the first day of March 1397 as \#51, whereas LEE10 identified it as \#50 on the basis of the calendar calculation of the Datong calendar ${ }^{7}$. However, currently we could not find any decisive source to verify the authenticity of the SCs of the first days of March 1397, May 1399, and December 1440.

However, Bigo indicated that since the beginning of the Joseon dynasty, its court used the same new moon day as the Ming dynasty. Thus, we think that the SCs of the Joseon dynasty might have been the same as those of China until 1442, at least when considering the compilation year of Chiljeongsan Naepyeon ${ }^{15}$ (Inner Part of a Korean Astronomical Calendar; see Lee 2008). According to Dong (1974), in China, the SC of the first day of March 1397 was \#50. The same argument can be applied to the SCs of the first days of May 1399 and December 1440, which were \#08 and \#06, respectively. 
Table 1.

Summary of the calendar day showing disagreements in the SCs of the new moon day between AHN09 and this study.

\begin{tabular}{|c|c|c|c|c|c|}
\hline \multirow{2}{*}{\multicolumn{3}{|c|}{$\begin{array}{c}\text { Calendar Date } \\
\text { (Lunisolar Calendar) }\end{array}$}} & \multicolumn{2}{|c|}{ Sexagenary cycle } & \multirow{3}{*}{$\begin{array}{l}\text { Sources } \\
\text { Bigo, Dong (1974) }\end{array}$} \\
\hline & & & \multirow{2}{*}{$\begin{array}{l}\text { AHN09 } \\
\# 51\end{array}$} & \multirow{2}{*}{$\begin{array}{l}\text { this study } \\
\# 50\end{array}$} & \\
\hline 1397 & Mar. & 1 & & & \\
\hline 1399 & May & 1 & \#07 & \#08 & Bigo, Dong (1974) \\
\hline 1430 & Apr. & 1 & $\# 07$ & \#08 & Sillok \\
\hline 1440 & Dec. & 1 & $\# 07$ & $\# 06$ & Bigo, Dong (1974) \\
\hline 1444 & Dec. & 1 & \#43 & $\# 42$ & Spirit-path stele \\
\hline 1530 & Feb. & 1 & $\# 58$ & $\# 59$ & $\mathrm{DD}^{b}$ \\
\hline 1597 & Sep. & 1 & $\# 25$ & $\# 26$ & $\mathrm{NI}^{c}$, Almanac \\
\hline 1602 & Sep. & 1 & $\# 57$ & $\# 56$ & $\mathrm{DS}^{d}, \mathrm{BJR}^{e}$ \\
\hline 1652 & Sep. & 1 & $\# 07$ & \#06 & Almanac \\
\hline 1652 & Oct. & 1 & \#37 & \#36 & Almanac \\
\hline 1677 & Oct. & 1 & $\# 42$ & $\# 41$ & Almanac \\
\hline 1698 & Nov. & 1 & \#09 & \#08 & Almanac, $\mathrm{GCI}^{f}$ \\
\hline 1709 & Feb. & 1 & $\# 40$ & \#39 & Almanac, $\mathrm{GCI}^{f}$ \\
\hline 1727 & Mar. $^{a}$ & 1 & $\# 55$ & $\# 54$ & Almanac \\
\hline 1730 & Apr. & 1 & $\# 35$ & $\# 36$ & Almanac \\
\hline 1751 & Nov. & 1 & $\# 60$ & \#01 & Sillok, JDI ${ }^{g}$ \\
\hline 1778 & Apr. & 1 & $\# 27$ & $\# 28$ & Almanac, IS $^{h}$ \\
\hline
\end{tabular}

${ }^{a}$ Intercalary month, ${ }^{b}$ Daemyeong Daetongryeok
${ }^{c}$ Nanjung Ilgi ${ }^{10}$ (Diary in the Midst of War), ${ }^{d}$ Dongak Seonsaengjip ${ }^{11}$ (Collected Works of Master Dongak), ${ }^{e}$ Baekjungryeok ${ }^{4}$ (refer to LEE10), ${ }^{4}$ Gyeongjong Chungung Ilgi ${ }^{12}$ (Logs on King Gyeongjong as Crown Prince), g Jangheonseja Donggung Ilgi 313 (Logs on Prince Jangheon as Crown Prince), ${ }^{h}$ Ilseongrok $^{14}$ (Records of Daily Reflection)

\subsection{April 1430 and December 1444}

As mentioned above, Chiljeongsan Naepyeon ${ }^{15}$ was compiled around 1442. Therefore, we believe that the SC of the first day of April 1430 is also the same as that of China (and that used by LEE10).

Nonetheless, we found historical accounts supporting the results of LEE10 from Sillok. It is a well known fact that King Sejong was born on April 10, 1397. If the SC of the first day of April 1430 was \#07, as suggested by AHN09, then the 10th day would become \#16. However, Sillok's record of the \#17 day indicates that the birthday ceremony of King Sejong was stopped owing to the rain. Therefore, if the SC of the first day of April 1430 is \#08, as suggested by LEE10, then Sillok's record can be naturally explained.

Sillok also talks about the death of Yeo Yi, the fifth son of King Sejong (i.e., Prince Gwangpyeong), in the record of the \#49 day of December 1444 (i.e., the 7th day according to AHN09, but the 8th day according to LEE10). However, we know Prince Yeo Yi died on the 8th day when referencing his spirit-path stele, which was built in 1574, approximately 130 years after his death (see Fig. 1, also Seoul Metropolitan Government 1987).

\subsection{February 1530 and September 1597}

Differing from previous cases, Sillok states that the \#58 day is the new moon day of February 1530. However, a book preserved in the Dongguk University Library, entitled 'Daemyeong Daetongryeok'9 (Datong Calendar of Great Ming; publisher and publication year are unknown), contains brief calendar data that includes the SC of the first day of each month from 1454 to 1537 (Kim 2010). According to this book, the SC of the first day of February 1530 is \#59; this corresponds with the information provided by LEE10. It is known that Sillok contains some errors regarding the SC of days (see Han 1997; Ahn et al. 2000). In addition, as presented in Table 1, the SCs of LEE10 are the same as those of China during matching periods. In conclusion, we believe that additional studies are required to confirm the SC of the first day of February 1530.

In the case of September 1597, King Seonjo's volume of Sillok also records the \#25 day as the new moon day. 


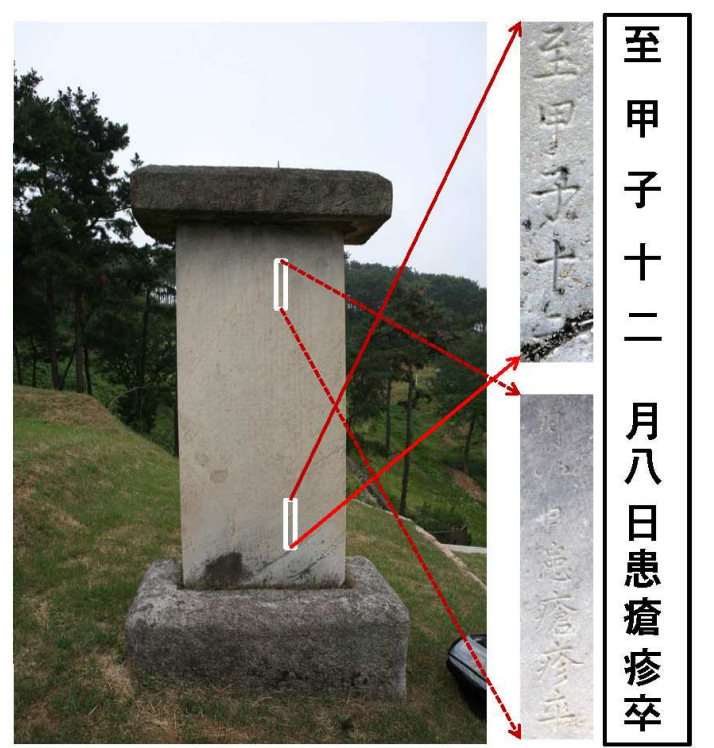

Fig. 1. - The spirit-path stele of Prince Gwangpyeong showing the date of his death (source: author).

On the other hand, its revised volume states that \#26 day is the new moon day. In addition, General Sunshin Lee's Nanjung Ilgi ${ }^{10}$ (Diary in the Midst of War) states that the SC of the first day of September 1597 is \#26 (Rho 2010). Furthermore, from the extant astronomical almanac of the year 1597 , we can reconfirm the SC of the year 1597 as \#26 (Korea Mental Culture Research Institute 1994).

\subsection{September 1602}

Sillok records indicate that the \#27, \#57, and \#26 are the SCs of the new moon days of August, September, and October 1602, respectively. AHN09 adopted the same SCs based on their principle of giving top priority to Sillok accounts. In this case, the lengths of August and September are 30 and 29 days, respectively. As an example to illustrate errors of the SC in the Sillok, the SC of the last day of September is the same as the first day of October, which is \#26.

On the other hand, LEE10 suggested the same SCs as Sillok, which account for August and October; however, it is \#56 for September. This means that the SC of September 22 is \#17 $(=56+21-60)$, which include data up to the 30th day of the month. Those facts are well matched with the records of Dongak Seonsaengjip ${ }^{11}$ (Collected Works of Master Dongak, the pen name of Ahn-Nul Lee). According to his work, the SC of the 22th day of September is \#17 (see right hand in Fig. 2), and 30 days have been accounted for in this month as well (see left hand in Fig. 2).

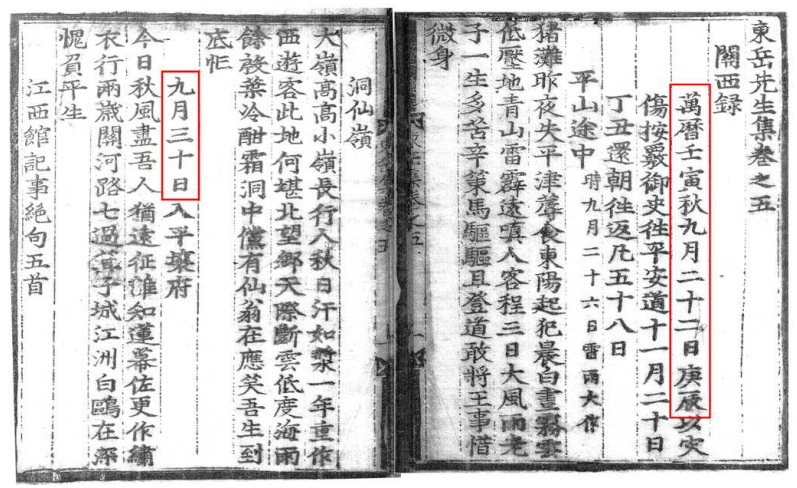

Fig. 2.- One part of Dongak Seonsaengjip ${ }^{11}$ showing the fact that the SC of the 22th day of September 1602 is \#17 (right), and there are 30 days in the month (left) (source: The National Library of Korea).

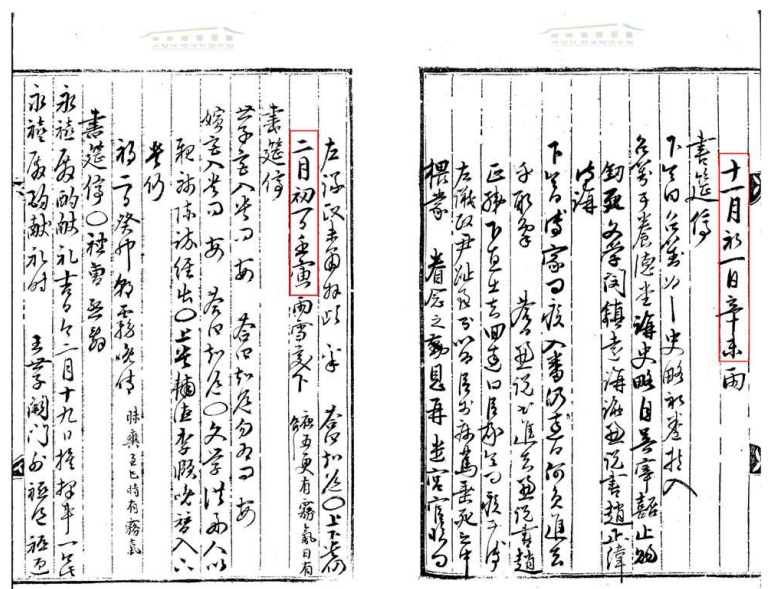

Fig. 3.- One part of Gyeongjong Chungung Ilgi ${ }^{12}$ that shows the SCs of November 1, 1698 (right), and February 1, 1709 (left) (source: Kyujanggak).

\subsection{September and October 1652, and October 1677}

Although Sillok lacks any account of the new moon day for September and October 1652, Ilgi says that the SCs of the first days of those months are \#06 and \#35, which are identical to the results of LEE10. In addition, Sillok says that the SC of the new moon day of October 1677 is \#42, whereas Ilgi lacks any account of the SC starting around early October. However, we can estimate the SC using Ilgi's accounts because it records not only the $\mathrm{SC}$, but also the date; whereas Sillok only has records of the SC. Because Ilgi says that the SC of the 5th day of October 1677 is \#45, the SC of the first day should be \#41. Courtesy a private owner, we checked the SCs presented in the almanacs of the years, and found that the all SCs of Ilgi (and also in this study) correspond with those of the almanacs. 


\subsection{November 1698 and February 1709}

The new moon days of November 1698 and February 1709 also reflect the difference in the SC between Sillok and Ilgi: \#09 and \#40 in Sillok (and AHN09), and \#08 and \#39 in Ilgi (and this study). We found a tertiary historical literature, Gyeongjong Chungung Ilgi ${ }^{12}$ (Logs on King Gyeongjong as Crown Prince), that supports Ilgi's SCs. This work is the daily log of King Gyeongjong during his crown prince years, from 1690 to 1720 , and it is preserved in the Kyujanggak Institute For Korean Studies (hereafter Kyujanggak). In this work, the SCs of the first days of November 1698 , and February 1709, are in agreement with those of Ilgi, and also this study (see Fig. 3). In addition, we confirmed the SCs from the almanacs of 1698 (Kyujanggak collection) and 1709 (private collection). In particular, although the almanac preserved in Kyujanggak is that of 1698 , it is identified as 1638 .

\subsection{Intercalary March 1727 and April 1730}

Similar to the previous subsection, Sillok and Ilgi both state different SCs for the new moon days of intercalary March 1727 and April 1730: \#55 and \#35 in Sillok (and AHN09), and \#54 and \#36 in Ilgi (and this study). However, when we compared this to the almanacs of 1727 (private collection) and 1730 (Keimyung University Library), we find that the SCs of Ilgi, and of this study, are the correct ones. In Fig. 4, we present the almanac page showing the $\mathrm{SC}$ of the first day of April 1730.

\subsection{November 1751}

In Sillok, there are no accounts of early November 1751; however, the SC of the next month's new moon day is recorded as \#30. On the other hand, Ilgi records show that the SCs of the first days of November and December 1751 are \#60 and \#29, respectively. In the case of AHN09, they determined each SC as \#60 and \#30, respectively.

Nonetheless, when reviewing Ilgi's accounts, we found errors in the SCs during the last three months in 1751. Ilgi records show that the $\mathrm{SC}$ of the first day of October is \#31; this means that the number of days in the month was 29 days (as mentioned above, the SC of the first day of November is recorded as \#60). Yet, Ilgi records show that there are 30 days in October, and they also show that October 18 and 19 have the same SC of \#48 (see Fig. 5). Considering this error, the SCs of the first days of November and December become \#01 and \#30, respectively, as suggested in this study as well. The errors in Ilgi's SCs continue until December 28; however, they are corrected on the next day by skipping one $\mathrm{SC}^{\ddagger}$. Nonetheless, we found that there is no problem in the dates of each month. It is

\footnotetext{
$\ddagger$ In the database of Ilgi (e.g., http://swj.history.go.kr), these kinds
} of errors are corrected

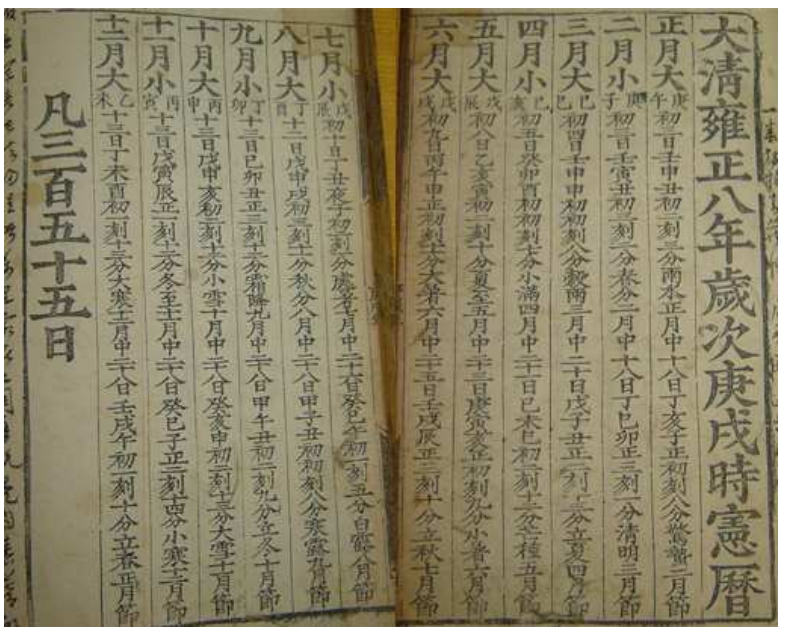

Fig. 4. - A page of the almanac showing the SC of the first day of April 1730 (source: Keimyung University Library).

known that the memorial ritual day of King Jungjong (or Gonghee) is November 15, this fact is recorded in the account of that day.

We could not verify the SC of the first day of November 1751 because, to the best our knowledge, the almanac of 1751 is currently not available. Instead, we find that the SC presented in Jangheonseja Donggung Ilgi ${ }^{13}$ (Logs on Crown Prince Jangheon or Sado) also agrees with our study.

\section{$3.9 \quad$ April 1778}

Differing from this study, the SC of the first day of April 1778 is \#27 in Sillok, Ilgi, and AHN09. However, we found that Ilgi has the same error as described in the previous subsection. In Ilgi's accounts, the 28th and 29th of March 1778 have the same SC, \#25. In addition, one SC leaps from \#41 to \#43 on April 16. Hence, the SC of the first day of April in Ilgi's accounts should be \#28. We confirmed the SC of that day from the account of Ilseongrok ${ }^{14}$ (Records of Daily Reflection), and from the almanac preserved in National Institute of Korean History (see Lee et al. 2008) for that year. According to both materials, the SC of the first day of April 1778 is \#28, as suggested by this study.

\section{SUMMARY}

When reviewing past time records, a calendar day provides fundamental data for understanding a nation and can be used in various fields, such as historical astronomy. Hence, the exact identification of the date when comparing a past calendar with a modern one (currently, the Gregorian calendar) is untenable; in reality many studies have been conducted on this subject. However, most of these studies are forced into the record of the new moon day in history books, such as Sillok, Ilgi, Bigo, and so forth. Recently, there has 


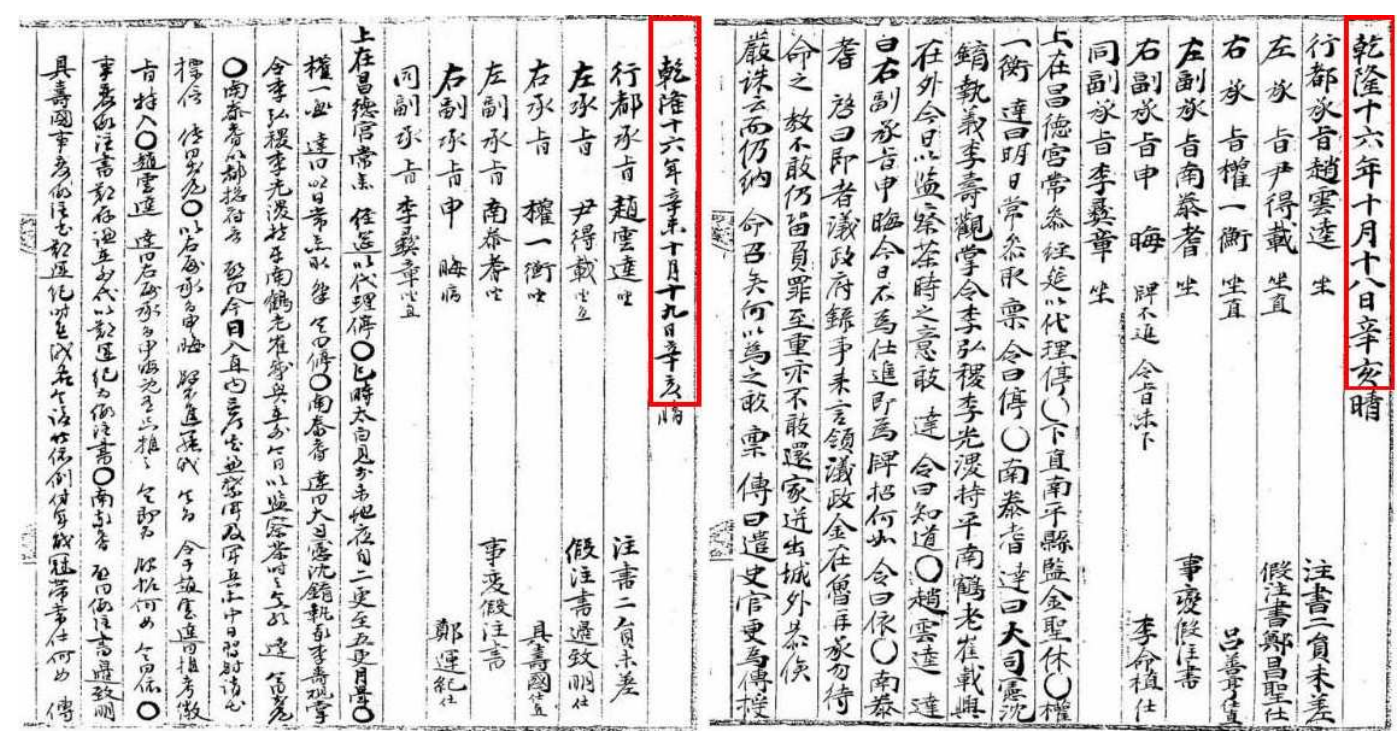

Fig. 5.- Ilgi's accounts of October 18 and 19 of 1751. Both days have the same SC, that is \#48, as mentioned in text (source: Kyujanggak).

been considerable progress in the study of traditional calendars. Databases of historical documents, such as astronomical almanac, are also being conducted.

In this paper, we re-examined the $\mathrm{SC}$ of the new moon day, i.e., the first day, in the lunisolar calendars of the Joseon dynasty $(1392-1910)$ by using the results of LEE10 and the data of Baekjungryeok ${ }^{4}$. We also compared the results of this study with those of AHN09. As a result, we found a total of 17 cases showing discrepancies and presented an argument for each case. Of the 17 discrepancies, we confirmed nine by using the almanacs from the respective period, and five by using historical materials, such as Sillok, Ilgi, Chungung Ilgi ${ }^{12}$, and so on. For the remains, we presented historical literatures supporting the results of this study. Additionally, we found that Ilgi is a better source than Sillok to study the calendar days of the Joseon dynasty, because the former contains information about the dates and corresponding SCs as well.

In conclusion, we believe that this study provides more accurate data when converting the calendar date of the Joseon dynasty into the Julian or Gregorian calendar date. In addition, we believe that this study will establish a strong foundation for studying other calendar days of different periods in Korea.

\section{ACKNOWLEDGMENTS}

Ki-Won Lee was supported by research grants from the Catholic University of Daegu in 2011. We deeply would like to extend our heartfelt appreciation to the librarians of the Kyujanggak Institute For Korean Studies, the National Institute of Korean History, and the Keimyung University for permitting us to read their valuable literature.
APPENDIX A. Glossary of Terms

\begin{tabular}{|c|c|c|c|}
\hline No. & Term & Abbrev. & Meaning \\
\hline 1 & $\begin{array}{l}\text { Joseon Wangjo Sillok } \\
\text { (朝鮮王朝實錄) }\end{array}$ & Sillok & Annals of the Joseon Dynasty \\
\hline 2 & $\begin{array}{l}\text { Seungjeongwon Ilgi } \\
\text { (承政院日記) }\end{array}$ & Ilgi & Daily Records of the Joseon Dynasty \\
\hline 3 & $\begin{array}{l}\text { Jeongbo Munheon Bigo } \\
\text { (賭補文獻储考) }\end{array}$ & Bigo & Explanatory Notes of Literary Document \\
\hline 4 & Baekjungryeok（百中曆） & BJR & One Hundred-Year Almanac \\
\hline 5 & Cheonseryeok（千歲歷） & & One Thousand-Year Almanac \\
\hline 6 & Manseryeok (萬歲曆) & & Ten Thousand-Year Almanac \\
\hline 7 & Datong Calendar (大統曆) & & A Calendar of the Ming Dynasty \\
\hline 8 & Shixian Calendar (時憲曆) & & A Calendar of the Ching Dynasty \\
\hline 9 & $\begin{array}{l}\text { Daemyeong Datongryeok } \\
\text { (大明大統曆) }\end{array}$ & $\mathrm{DD}$ & Datong Calendar of Great Ming \\
\hline 10 & Nanjung Ilgi（䰻中日記） & NI & Dairy in the Midst of War \\
\hline 11 & $\begin{array}{l}\text { Dongak Seonsaengjip } \\
\text { (東岳先生集) }\end{array}$ & DS & Collected Works of Master Dongak \\
\hline 12 & $\begin{array}{l}\text { Gyeongjong Chungung Ilgi } \\
\text { (景宗春宮日記) }\end{array}$ & GCI & Logs on King Gyeongjong as Crown Prince \\
\hline 13 & $\begin{array}{l}\text { Jangheonseja Donggung Ilgi } \\
\text { (莊獻世子東宮日記) }\end{array}$ & JDI & Logs on Prince Jangheon as Crown Prince \\
\hline 14 & Ilseongrok (日省錄) & IS & Records of Daily Reflection \\
\hline 15 & $\begin{array}{l}\text { Chiljeongsan Naepyeon } \\
\text { (十政算內編) }\end{array}$ & & Inner Part of A Korean Astronomical Calendar \\
\hline
\end{tabular}

APPENDIX B. Sexagenary Cycles

\begin{tabular}{|c|c|c|c|c|c|c|c|c|c|}
\hline 01 & 02 & 03 & 04 & 05 & 06 & 07 & 08 & 09 & 10 \\
\hline 甲子 & 乙丑 & 丙寅 & 丁卯 & 戊辰 & 己巳 & 庚午 & 辛未 & 壬申 & 癸酉 \\
\hline 11 & 12 & 13 & 14 & 15 & 16 & 17 & 18 & 19 & 20 \\
\hline 甲戌 & 乙亥 & 丙子 & 丁丑 & 戊寅 & 己卯 & 庚辰 & 辛巳 & 壬午 & 癸未 \\
\hline 21 & 22 & 23 & 24 & 25 & 26 & 27 & 28 & 29 & 30 \\
\hline 甲申 & 乙酉 & 丙戊 & 丁亥 & 戊子 & 己丑 & 庚寅 & 辛卯 & 壬辰 & 癸巳 \\
\hline 31 & 32 & 33 & 34 & 35 & 36 & 37 & 38 & 39 & 40 \\
\hline 甲午 & 乙未 & 丙申 & 丁酉 & 戊戊 & 己亥 & 庚子 & 辛丑 & 壬寅 & 癸卯 \\
\hline 41 & 42 & 43 & 44 & 45 & 46 & 47 & 48 & 49 & 50 \\
\hline 甲辰 & 乙巳 & 丙午 & 丁未 & 戊申 & 己酉 & 庚戊 & 辛亥 & 壬子 & 癸丑 \\
\hline 51 & 52 & 53 & 54 & 55 & 56 & 57 & 58 & 59 & 60 \\
\hline 甲寅 & 乙卯 & 丙辰 & 丁巳 & 戊午 & 己未 & 庚申 & 辛西 & 壬戊 & 癸亥 \\
\hline
\end{tabular}




\section{REFERENCES}

Ahn, Y. S., Han, B. S., Sim, K. J., \& Song, D. J. 2000, Arrangement of Chronological Tables on Choseon Dynasty (A.D. 1392 - 1910), JKAS, 33, 177

Ahn, Y. S., Han, B. S., Sim, K. J., \& Song, D. J. 2009a, Arrangement of Chronological Tables on the Joseon Dynasty (Paju: Korean Studies Information Co. Ltd.)

Ahn, Y. S., Lee, Y. B., Lee, Y. S., \& Han, B. S. 2009b, Arrangement of Chronological Tables on the Three Kingdoms (Paju: Korean Studies Information Co. Ltd.)

Ahn, Y. S., Sim, K. J., Song, D. J., Han, B. S., \& Yang, H. J. 2009c, Arrangement of Chronological Tables on the Goryeo Dynasty (Paju: Korean Studies Information Co. Ltd.)

Dong, Z. B. 1974, Zhongguo nianli jianpu (A Simplified Table of the Chinese Calendar) (Taipei: Yiwen Yinshuguan)

Han, B. S. 1987, Arrangement of Chronological Tables on Korea (Kyeongsan: Yeungnam University Press)

Han, B. S. 1997, A Look at the Calendar Day Presented in Goryeosa (History of the Goryeo Dynasty) and Joseon Wangjo Sillok, In Korean Calendar and Historical Astronomy ed. By Song, D. J. \& Ahn, Y. S. (Seoul: Kyungmunsa)

Han, B. S. 2001, Arrangement of Chronological Tables on Korea (Kyeongsan: Yeungnam University Press)

Kim, H. S. 2010, Publication and Printed Books of Almanac in Joseon Dynasty, MSc Thesis (Daegu: Kyungpook National University Press)

Kim, J. T. 2002, A Look at the Kyeongjinyeon Daetongryeok, Journal of the Study on Life and Civilization, 7,69

Korea Astronomy and Space Science Institute 2010, Korean Astronomical Almanac of the year 2011 (Seoul: Namsandang)

Korea Mental Culture Research Institute. 1994, Old Literature Collection Vol. 18 (Seongnam: Yuseong Press)

Lee, E. H. 1997, Astronomical Almanacs of the Joseon Dynasty, In Korean Calendar and Historical Astronomy ed. by Song, D. J. \& Ahn, Y. S. (Seoul: Kyungmunsa)

Lee, E. S. 1985, Analysis of the Principle of Calendrical Method (Seoul: Jeongeumsa)

Lee, K.-W. 2008, On the Study of the Organization and the Examination System of Gwansanggam in the Joseon Dynasty: Focusing on the Astronomy Division, The Journal of the Korean Earth Science Society, 29, 98

Lee, K.-W., Yang, H.-J., \& Park, M.-G. 2008, Astronomical Books and Charts in the Book of Bibliographie Coréenne, JASS, 25, 199
Lee, K.-W., Ahn, Y.-S., Mihn, B.-H., \& Shin, J.-S. 2011, Database Construction and Textual Analysis of Korean Astronomical Almanacs, PKAS, 26, 1

Lee, K.-W., Ahn, Y.-S., Mihn, B.-H., \& Lim, Y.-R. 2010, Study on the Period of the Use of Datong-li in Korea, JASS, 27, 55

Rho, S. S. 2010, Complete Translation of Nanjung Ilgi (Seoul: Mineumsa)

Seoul Metropolitan Government. 1987, Compendium of Seoul City's Inscriptions (Seoul: Samseong Press Co. Ltd.)

Yang, H. J., Ahn, Y. S., Sim, K. J., Han, B. S., \& Song, D. J. 1999, Arrangement of Chronological Tables on Koryo Dynasty (A. D. 918 - 1392), PKAS, 14, 129 